\title{
Gonadotropin-mediated chemoresistance: Delineation of molecular pathways and targets
}

\author{
Suchismita Sahoo, Poonam Singh, Beneeta Kalha, Om Singh and Rahul Pal
}

\begin{abstract}
Background: Human chorionic gonadotropin (hCG) has essential roles in pregnancy. Reports linking hCG in non-trophoblastic tumors with poor patient prognosis has spurred interest in patho-physiological roles the hormone might play.
\end{abstract}

Methods: The ability of hCG to prevent tumor cell death and sustain viability in the presence of chemotherapeutic drugs was assessed and potential synergies with TLR ligands explored. hCG-induced up-modulation of genes involved in chemoresistance was documented and targets validated by siRNA knock-down. Whether hCG could drive collaboration between tumor cells and macrophages in the production of IL-6 and consequent chemoresistance was assessed. The effects of concurrent anti-hCG immunization and chemotherapy on the growth of syngeneic murine tumors were evaluated.

Results: hCG maintained basal levels of cytokine secretion by tumor cells exposed to chemotherapeutic drugs, and enhanced viability and proliferation; pre-treatment with hCG also decreased apoptosis, as assessed by Annexin-V binding and the cleavage of caspase 3. While co-incubation with hCG along with several TLR ligands mediated heightened chemo-resistance, TLR-2/6 and TLR-9 ligands increased the phosphorylation of JNK, and TLR-2 and TLR-8 ligands the phosphorylation of ERK in presence of hCG and curcumin, providing evidence of tri-molecular synergy. The hormone increased the transcription and/or expression of molecular intermediates (SURVIVIN, HIF-1a, PARP-1, BCl-2, c-FLIP, KLK-10, XIAP, C-IAP-1) associated with chemo-resistance and increased levels of stress modulators (PON2, HO-1, HSP27 and NRF-2). siRNAs to SURVIVIN, NRF-2, HO-1 and HIF-1a attenuated hCG-mediated chemo-resistance. hCG-conditioned tumor cell supernatants induced heightened secretion of IL- 6 and TNF-a from peripheral blood adherent cells and secreted IL-6 imparted chemo-resistance to naïve tumor cells. Co-administration of curcumin along with an anti-hCG vaccine (hCG $\beta$ conjugated to Tetanus Toxoid (TT)) to mice carrying syngeneic tumors resulted in significantly enhanced benefits on animal survival; synergy was demonstrated between anti-hCG antibodies and curcumin in the reduction of tumor cell viability.

Conclusions: The data suggest that hCG, via direct as well as collaborative effects with TLR ligands and accessory cell-secreted cytokines, mediates chemo-resistance in gonadotropin-sensitive tumors and outlines the potential benefits of combination therapy.

Keywords: Human chorionic gonadotropin, Ectopic secretion, Prognosis, Chemoresistance, Immunotherapy

\footnotetext{
* Correspondence: rahul@nii.ac.in

Immunoendocrinology Lab, National Institute of Immunology, Aruna Asaf Ali

Marg, JNU Complex, New Delhi Delhi-110067, India
} 


\section{Background}

Chorionic gonadotropin, a glycoprotein hormone specific to primates, is possibly the first maternal indicator of pregnancy. It extends the life of the corpus luteum to elicit the continued secretion of progesterone [1], enables implantation and trophoblast invasion, and supports angiogenesis [2, 3].

Several non-trophoblastic tumors have been shown to express human chorionic gonadotropin (hCG) or its constituent subunits [4-6]. Data are suggestive of hCG playing a role in tumor growth by autocrine/paracrine mechanisms. Incubation of bladder cancer cells with hCG $\beta$ leads to dose-dependent proliferation [7], and tumor-derived hCG is associated with unresponsiveness to treatment and decreased survival [8, 9]. Further, hCG $\beta$-positive patients respond poorly to radiotherapy [10] and its presence is associated with an aggressive cancer phenotype and high metastatic potential [11]. Evidence for a pro-tumorigenic role for hCG has also been provided by transgenic models; mice expressing hCG develop gonadal neoplasia and extra-gonadal tumors [12].

Chemo-resistance can result from numerous mechanisms, including decreased intracellular drug concentrations, an augmented ability to repair DNA damage or endure stress, as well as the prevention of cell death. TLR ligands [13], HIF-1 $\alpha$ [14], Inhibitor of Apoptotic Proteins [15] and pro-inflammatory cytokines [16] have been linked with chemo-resistance and tumorigenesis. The tumor microenvironment, including associated nontransformed cells, can also contribute towards creation of a pro-tumorigenic milieu [17].

Results obtained during this study support the notion that exogenous gonadotropin can enhance tumor cell growth and viability while additionally mediating chemoprotection, and also identify potential molecular intermediates. Further, the data also suggests that third-party influences, such as enhanced signaling via toll-like receptors and inflammatory cytokines secreted by non-transformed accessory cells, can collaborate to enhance hCG-mediated effects. Finally, evidence is provided to suggest that potent anti-hCG vaccination, as an adjunct to conventional chemotherapy, may hold promise in the treatment of cancers rendered chemo-resistant due to the action of gonadotropin.

\section{Methods}

\section{Ethics statement}

This study was carried out in strict accordance with protocols approved by the Institutional Animal Ethics Committee (IAEC) of the National Institute of Immunology (IAEC Number: 231/10) and according to national and international ethical guidelines.

\section{Animals}

Six week-old inbred female C57BL/6 mice were obtained from the Small Animal Facility of the National Institute of Immunology, New Delhi.

\section{hCG, drugs, cell lines}

Though recombinant $\mathrm{hCG}$ has been established to be biologically potent in conventional assays (on reproductive tissues and processes) by several investigators, it contains carbohydrates that are distinct from those on native hCG due to variations in the extent of oligosaccharide branching and sialylation. Since this study aimed to evaluate the chemo-protective effects of hCG on tumor cells (which have thus far not been described in any detail), it was reasoned appropriate to employ native hCG so as to expose cells to as natural a biological stimulus as possible. Native hCG (Wyong Biologicals) was subjected to physical (by SDS-PAGE and HPLC), immunological (by a hCG $\beta$-specific radioimmunossay and Western blot) and biological (by radioreceptor assay and Leydig cell bioassay) characterization; the preparation did not contain significant amounts of free hCG $\beta$ and was independently assessed to express an activity of $\cong 11,000-13,000 \mathrm{IU} / \mathrm{mg}$ against relevant hCG standards, the same range as reported for recombinant hCG when the contribution of carbohydrates is taken into account. hCG was employed over a range of concentrations $(10 \mu \mathrm{g} / \mathrm{ml}-100 \mathrm{ng} / \mathrm{ml}$ or $\cong 110 \mathrm{IU} / \mathrm{ml}-1.1 \mathrm{IU} / \mathrm{ml})$.

Curcumin was obtained from Sanat Products; Tamoxifen, Etoposide and 5-Fluorouracil (5-FU) were obtained from Enzo Life Sciences. Human (Colorectal: COLO205 (CCL-222); Lung: ChaGo-K-1 (HTB-168)) and murine (Lewis Lung: LLC1 (CRL-1642); Melanoma: B16 (CRL-6323); Myeloma: SP2/O (CRL-1581)) cell lines were obtained from ATCC and used within six months of receipt or resuscitation. Human cell lines were authenticated by STR at ATCC as per convention. All cell lines were also authenticated by assessment of phenotypic, morphological and growth characteristics, and were mycoplasma-free. Cells were cultured in RPMI 1640 (Life Technologies) or DMEM along with $10 \%$ fetal bovine serum (Biological Industries).

\section{Effects of hCG on tumor cell viability, proliferation}

B16, COLO-205, SP2/O and ChaGo-K-1 cells $\left(5 \times 10^{4}\right)$ were incubated with hCG for $24 \mathrm{~h}$. $50 \mu \mathrm{l}$ of $3-(4,5-$ Dimethylthiazol-2-yl)-2, 5-diphenyltetrazolium bromide (MTT, Sigma) was then added and the reaction arrested using DMSO. Absorbance was assessed at $550 \mathrm{~nm}$. Data (for this and subsequent MTT experiments) was plotted as percentage viability compared with relevant controls. Tumor cells pre-exposed to hCG for $24 \mathrm{~h}$ were incubated with $\left[{ }^{3} \mathrm{H}\right]$-Thymidine $(0.5 \mu \mathrm{Ci} /$ well $)$, followed by 
incubation for an additional $18 \mathrm{~h}$. Cell-associated radioactivity was assessed in a $\beta$-counter.

Effects of hCG on chemotherapeutic drug-induced loss of tumor cell viability, apoptosis

COLO-205, ChaGo-K-1, SP2/O and LLC1 cells preexposed to hCG for $24 \mathrm{~h}$ were treated with curcumin $(10 \mu \mathrm{M}-160 \mu \mathrm{M}$, Sigma) or tamoxifen $(0.1 \mu \mathrm{M}-40 \mu \mathrm{M}$, Sigma) for $24 \mathrm{~h}$ and $48 \mathrm{~h}$ respectively, and MTT assays were carried out. In parallel experiments, reactivity of cells to Annexin- $\mathrm{V}$ was determined by flow cytometry; briefly, cells were incubated with Annexin-V-FITC (BD Biosciences) for $15 \mathrm{~m}$ and run on a flow cytometer (BD-LSR; BD Biosciences). Data was analysed using WinMDi 2.9 software.

\section{Effect of hCG on activation of caspase-3}

ChaGo-K-1 cells were incubated with hCG for $24 \mathrm{~h}$ and subsequently with curcumin $(40 \mu \mathrm{M})$ for $24 \mathrm{~h}$. Conversion of pro-caspase 3 to active (cleaved) caspase 3 was assessed using an apoptosis array kit (R\&D Systems). Reactive spots were visualized by enhanced chemiluminescence (ECL; Biological Industries).

\section{Combined effects of hCG and TLR ligands on chemotherapeutic drug-induced loss of tumor cell viability and on cell signaling \\ Cell Viability}

COLO-205 cells pre-exposed to hCG for $24 \mathrm{~h}$ were incubated with individual TLR ligands (Invivogen; TLR 1/2: Pam3CSK4 (1 $\mu \mathrm{g} / \mathrm{ml})$; TLR2: HKLM $\left(10^{8}\right.$ cells $\left./ \mathrm{ml}\right)$, TLR3: Poly I:C $(10 \mu \mathrm{g} / \mathrm{ml})$; TLR4: LPS $(10 \mu \mathrm{g} / \mathrm{ml})$; TLR5: Flagellin $(10 \mu \mathrm{g} / \mathrm{ml})$; TLR2/6: FSL-1 $(1 \mu \mathrm{g} / \mathrm{ml})$, TLR7: Imiquimod (5 $\mu \mathrm{g} / \mathrm{ml})$; TLR8: ssRNA40 $(10 \mu \mathrm{g} / \mathrm{ml})$; TLR9: ODN2006 $(5 \mu \mathrm{M})$ ) for $24 \mathrm{~h}$. Cellular viability upon subsequent treatment with curcumin (at $40 \mu \mathrm{M}$ ) was assessed at $24 \mathrm{~h}$.

\section{Cell Signaling}

COLO-205 cells were incubated with hCG for $24 \mathrm{~h}$ prior to incubation with individual TLR ligands (at the concentrations indicated above) for $24 \mathrm{~h}$. Curcumin (at $40 \mu \mathrm{M})$ was then added and a further incubation carried out for $24 \mathrm{~h}$. Cells were then harvested and lysates probed with monoclonal antibodies specific for total and phosphorylated ERK and JNK (Santacruz Biotech) by Western blot. Reactive moieties were visualized by enhanced chemiluminescence (ECL; Biological Industries).

\section{Mediators of hCG-induced chemo-resistance Identification}

$1 \mu \mathrm{g}$ total RNA, obtained from ChaGo-K-1 cells preexposed to hCG, was reverse transcribed into cDNA using oligo-dT and reverse transcriptase (Promega).
Primers for amplification of human PARP-1, BCL-2, HIF$1 \alpha$, SURVIVIN, KLK-10, c-FLIP, different TLRs and $\beta-$ ACTIN (as control) are listed in Additional file 1: Figure S1. For PCR, a $15 \mathrm{~m}$ denaturation step at $95{ }^{\circ} \mathrm{C}$ was followed by 35 cycles of three steps each: $95{ }^{\circ} \mathrm{C}$ for $1 \mathrm{~m}$, annealing for $1 \mathrm{~m}$, extension at $72{ }^{\circ} \mathrm{C}$ for $1 \mathrm{~m}$, followed by final extension at $72{ }^{\circ} \mathrm{C}$ for $10 \mathrm{~m}$.

Cellular lysates, obtained from ChaGo-K-1 cells preexposed to hCG, were electrophoresed and subsequently transferred onto nitrocellulose membranes (mdi), and probed with monoclonal antibodies specific to PARP-1, BCL-2, HIF-1 $\alpha$, SURVIVIN, KLK-10 and c-FLIP. (Santacruz Biotech); reactivity, subsequent to the addition of secondary antibodies (Jackson ImmunoResearch), was visualized by enhanced enzymatic chemi-luminescence. Expression levels of the molecules subsequent to the incubation of ChaGo-K-1 cells with hCG were also assessed by flow cytometry; cells were permeabilized before incubation with specific antibodies for $1 \mathrm{~h}$ at $4{ }^{\circ} \mathrm{C}$. After addition of FITC-conjugated secondary antibodies (Jackson ImmunoResearch), samples were run on a flow cytometer and data analyzed by WinMDi 2.9 software.

ChaGo-K-1 cells were incubated with hCG for $24 \mathrm{~h}$ and subsequently to curcumin $(40 \mu \mathrm{M})$ for $24 \mathrm{~h}$. Effects on thirty five mediators involved in apoptosis and stress regulatory responses were assessed using an apoptosis array kit (R\&D Systems). Reactive spots were visualized by enhanced chemiluminescence.

\section{Validation}

ChaGo-K-1 cells were transiently transfected with either control scrambled RNA (scRNA) or siRNA directed against HIF-1A, SURVIVIN, NRF-2 and HO-1 (Santacruz Biotech). Briefly, scRNA or siRNA was diluted in transfection medium to $30 \mathrm{pM}, 60 \mathrm{pM}$ or $120 \mathrm{pM}$. The solution was mixed with transfection reagent, incubated for $30 \mathrm{~m}$ at room temperature and overlaid on ChaGo-K-1 cells, following which an incubation was carried out for $6 \mathrm{~h}$ at $37^{\circ} \mathrm{C}$. Medium supplemented with $20 \%$ FCS was added and a further incubation carried out for $16 \mathrm{~h}$. Cells harvested from two parallel experiments were assayed for decrease in mRNA (by semi-quantitative RTPCR) and protein (by Western blot) expression. The ability of hCG to mediate chemo-resistance in transfected cells was then assessed in a cell viability assay as outlined above.

\section{Assessment of the role of IL-6 in hCG-induced chemo- resistance}

ChaGo-K-1 and COLO-205 cells were incubated with recombinant IL-6 (at $50 \mathrm{ng} / \mathrm{ml}$; R\&D Systems) for $6 \mathrm{~h}$ and subsequently incubated with curcumin $(40 \mu \mathrm{M})$ for $24 \mathrm{~h}$. Viability was assessed by MTT. 
hCG tumor-conditioned medium (obtained upon incubation of ChaGo-K-1 and COLO-205 with hCG for $24 \mathrm{~h}$ ) was incubated with peripheral blood adherent cells (PBACs; obtained upon plastic adherence of human PBMCs) for $24 \mathrm{~h}$. Levels of IL- 6 and TNF- $\alpha$ in PBAC supernatants were determined by ELISA (eBiosciences). The ability of such PBAC supernatants to mediate resistance to curcumin (at $40 \mu \mathrm{M}$ ) in naïve ChaGo-K-1 and COLO-205 cells was assessed by MTT; the contribution of elicited IL- 6 to these effects was assessed using antiIL6 neutralizing antibodies (500 ng/ml; R\&D Systems).

\section{Effects of anti-hCG immunization and chemotherapy in tumor-bearing mice \\ Vaccine formulation}

hCG $\beta$ was conjugated to tetanus toxoid (TT) in a molar ratio of 6:1 using the cross-linker sulfosuccinimidyl 6[32) -pyridyldithio)-propionamido] hexanoate (LC-sulpho-SPDP; Pierce) as previously described [18]. The $\mathrm{hCG} \beta$ content in the conjugate was estimated by radioimmunoassay. Briefly, increasing amounts $(0.125 \mathrm{ng}$ to $4 \mathrm{ng}$ ) of hCG or dilutions of the hCG $\beta$-TT conjugate were incubated at $4{ }^{\circ} \mathrm{C}$ for $18 \mathrm{~h}$ with a murine antihCG $\beta$ specific monoclonal antibody in the presence of ${ }^{125} \mathrm{I}-\mathrm{hCG}(\cong 15,000 \mathrm{dpm}$; specific activity: 40-60 $\mu \mathrm{Ci} / \mu \mathrm{g})$ and $4 \%$ normal horse serum. The antibody bound fraction was precipitated by adding PEG 8000 (12.5\% final concentration), separated by centrifugation at $1500 \mathrm{~g}$ at $4{ }^{\circ} \mathrm{C}$ for $20 \mathrm{~m}$ and counted for radioactivity. The concentration of hCG $\beta$ in the conjugate was estimated with reference to the standard curve.

hCG $\beta$-TT was adsorbed on Alhydrogel (Superfos; $1 \mathrm{mg}$ protein/ml slurry) by incubation on an end-to-end rocker at $4{ }^{\circ} \mathrm{C}$ for $16 \mathrm{~h}$. Adsorption efficiency was greater than $95 \%$.

Mycobacterium indicus pranii (MIP) was grown in Middlebrook 7H9 media (BD Difco) supplemented with $10 \%$ albumin-dextrose complex enrichment (BD Difco), $0.02 \%$ glycerol, and $0.05 \%$ Tween-80. Bacteria were killed by autoclaving at $121{ }^{\circ} \mathrm{C}$ at a pressure of $15 \mathrm{lb} / \mathrm{in}^{2}$ for $20 \mathrm{~m}$.

\section{Intervention}

Groups of female inbred C57BL/6 mice were subcutaneously implanted with syngeneic LLC1 cells $\left(4 \times 10^{4}\right.$ cells/ mouse). On the same day, mice received a subcutaneous injection of $2 \mu \mathrm{g}$ alhydrogel-adsorbed hCG $\beta$-TT emulsified in Incomplete Freund's Adjuvant (IFA; Life Technologies) along with MIP $\left(10^{8}\right.$ cells; intramuscular), hereafter referred to as immunotherapy. Three injections were administered at monthly intervals. A second group of animals was co-administered curcumin $(2.5 \mathrm{mg} / \mathrm{kg}$; intra-peritoneal, thrice weekly) along with immunotherapy. Additional groups of animals were treated with curcumin, the vehicles, or were left untreated. Tumor volumes $\left(4 / 3 \pi r^{3} ; r=(\right.$ length + width $\left.) / 4\right)$ were recorded at periodic intervals.

\section{Assessment of synergy between anti-hCG antibodies and curcumin}

In vitro experiments were conducted to demonstrate whether anti-hCG antibodies and curcumin exerted synergistic effects on ChaGo-K-1 cells. Anti-hCG antibodies $(0-10 \mu \mathrm{g} / \mathrm{ml})$ and curcumin $(0-80 \mu \mathrm{M})$ were added alone and in combination to ChaGo-K-1 cells and an incubation carried out for $24 \mathrm{~h}$. MTT assays were carried out as described above. Whether the effects obtained upon the combination of both moieties constituted synergy was calculated on the basis of the Combination Index (C.I.) as:

$$
\frac{\mathrm{C}_{50} \text { antibody }}{\mathrm{IC}_{50} \text { antibody }}+\frac{\mathrm{C}_{50} \text { curcumin }}{\mathrm{IC}_{50} \text { curcumin }}
$$

where $\mathrm{IC}_{50}$ antibody and $\mathrm{IC}_{50}$ curcumin refer to respective concentrations resulting in $50 \%$ inhibition in MTT assays (when added alone), and $\mathrm{C}_{50}$ antibody and $\mathrm{C}_{50}$ curcumin refer to respective antibody and curcumin concentrations (when added in combination) resulting in $50 \%$ inhibition in MTT assays. Values of C.I. less than one signify synergy, equal to one additivity, and greater than one, antagonism [19].

\section{Statistical Analysis}

Data are expressed as arithmetic mean \pm SD. Statistical significance was assessed using the unpaired Student's $t$ test; the data distribution in the samples assayed was normal. Animal survival was analyzed by the method of Kaplan-Meier.

\section{Results}

\section{Effects of hCG on tumor cell viability, proliferation}

B16, COLO-205, SP2/O and ChaGo-K-1 cells were incubated with hCG for $24 \mathrm{~h}$; viability and proliferative responses were subsequently assessed. Human and murine tumor cells exposed to hCG demonstrated increased viability as well as increased rates of cell proliferation (Fig. 1a and b).

\section{Effects of hCG on chemotherapeutic drug-induced loss of tumor cell viability}

Based on the association of hCG with increased chemoresistance $[9,20]$, whether hCG can directly induce chemo-resistance in tumor cells was ascertained. hCG pre-exposure resulted in a significant reduction in druginduced decrease in viability in both human and murine tumor cells, though individual responses varied (Fig. 1c); while hCG protected COLO-205 cells from only low to 


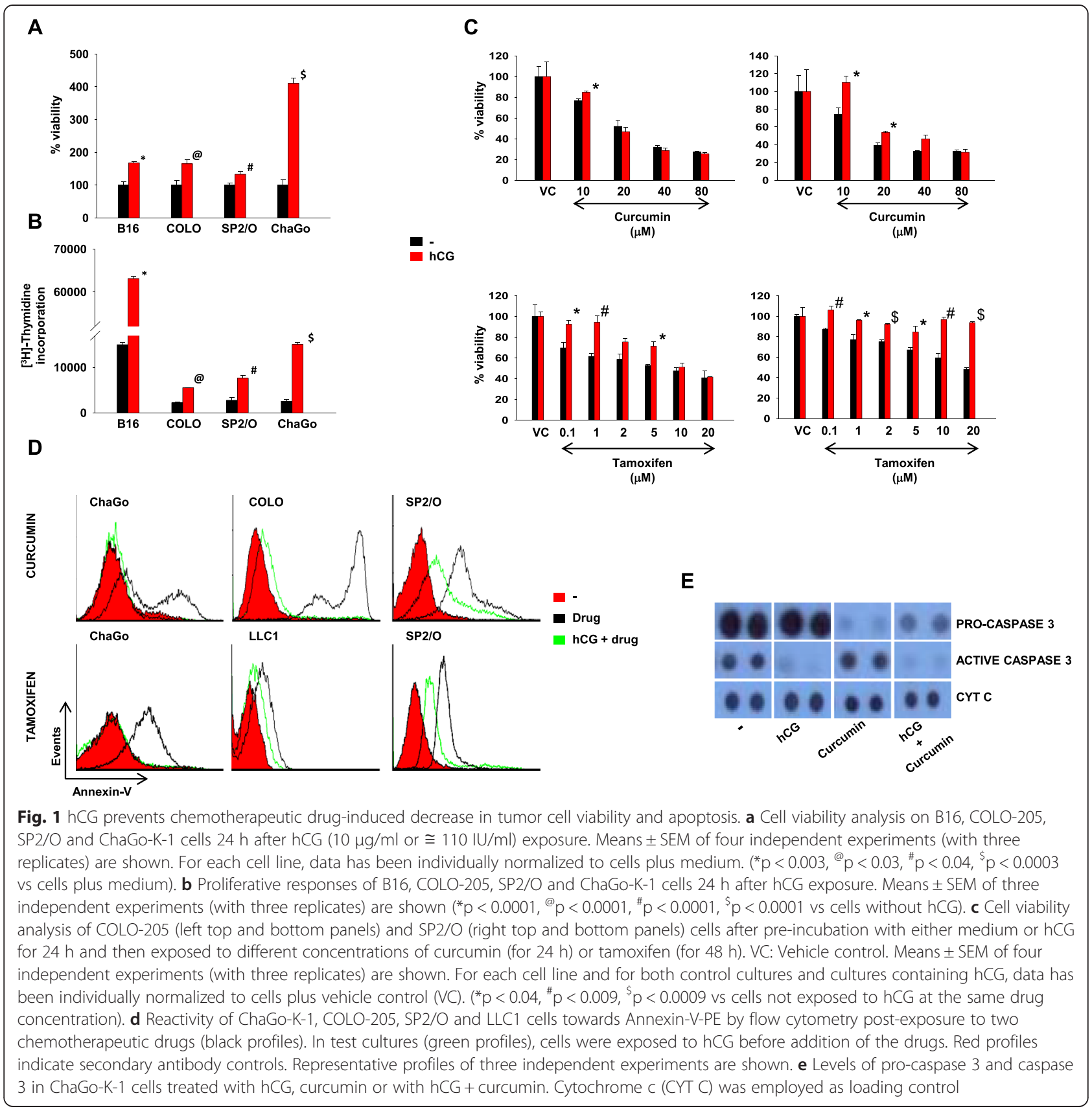

moderate concentrations of curcumin and tamoxifen, SP2/O cells exposed to even high concentrations of tamoxifen remained significantly protected.

\section{Effects of hCG on chemotherapeutic drug-induced apop- tosis of tumor cells}

Drug resistance is a multifactorial process and is characterized by dysregulation of the equilibrium between cell survival and apoptosis [21]. Whether hCG can effect chemotherapeutic drug-induced apoptosis of tumor cells was assessed; four tumor cell lines (COLO-205, SP2/O, ChaGo-K-1, LLC1) and two drugs (curcumin, tamoxifen) were employed. Pre-exposure to hCG dramatically reduced the binding of Annexin- $\mathrm{V}$ in cells incubated with the drugs (Fig. 1d).

Incubation of ChaGo-K-1 cells with curcumin significantly reduced levels of pro-caspase 3 compared to control cells, as expected. Significantly, pre-incubation with hCG reduced levels of active (cleaved) caspase 3. In cells incubated with both curcumin and hCG, levels of procaspase 3 were higher and levels of active (cleaved) caspase 3 lower compared to cells treated with curcumin alone (Fig. 1e). These results suggest that hCG mediates significant anti-apoptotic effects. 
Effects of hCG on TLR expression and the combined effects of hCG and TLR ligands on chemo-resistance Increasing evidence points to a potential role for TLRs in tumorigenesis and chemo-resistance [13, 22]. The combined effects of hCG and TLR ligands on chemoresistance was assessed. Incubation with hCG led to increases in mRNA and protein levels of TLR1, TLR3, TLR8 and TLR9 in COLO-205 cells (Additional file 2: Figure S2). Treatment of these cells with TLR ligands (in the presence or absence of drugs) did not affect viability over respective control cultures. COLO-205 cells preexposed to hCG, then to individual TLR ligands and subsequently to curcumin, demonstrated increased viability in comparison to appropriate controls; interestingly, in several instances, the addition of TLR ligands along with hCG resulted in greatly enhanced chemo-protection (Fig. 2a). Qualitatively similar effects were observed when tamoxifen was employed as the chemo-therapeutic agent (Additional file 3: Figure S3).

To gain further insight into the observed enhancement in chemo-protective effects, the phosphorylation of ERK and JNK upon the addition of hCG, individual TLR ligands and curcumin (alone and in combination) was assessed; prominent data is discussed here. While individual addition of hCG and the TLR-9 ligand ODN2006 induced JNK phophorylation, these moieties in combination and in the additional presence of curcumin induced a synergistic increase. Similar synergism was observed when the

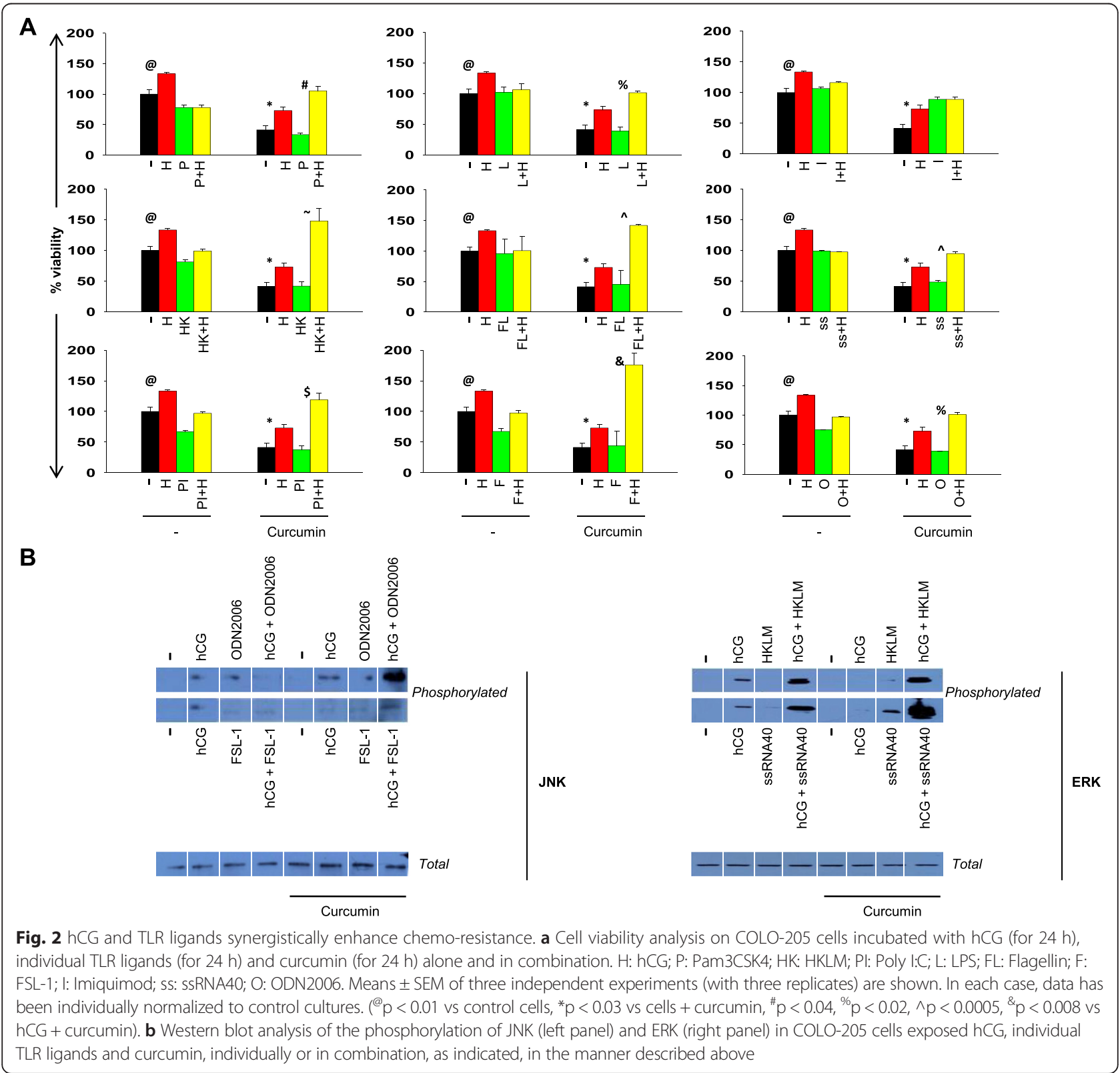


TLR6 ligand FSL-1 was added along with hCG and curcumin. While hCG induced the phosphorylation of ERK and ligands for both TLR-2 and TLR-8 (HKLM and ssRNA40 respectively) were ineffective (at $48 \mathrm{~h}$ post stimulation), hCG acted in synergy with both these ligands to enhance ERK phoshorylation. The addition of curcumin to hCG and ssRNA40 resulted in further enhancement (Fig. 2b). To summarize, both bimolecular (involving some TLR ligands and hCG) as well as tri-molecular (involving some TLR ligands, hCG and curcumin) synergies were observed, the potential significance of which is discussed below.

\section{Identification and validation of potential mediators of hCG-induced chemo-resistance}

Message and expression levels of molecules known to be associated with chemo-resistance and also known to be modulated by hCG (for the most part, in reproductive tissues) were evaluated. mRNA and protein levels of PARP-1, BCL-2, HIF-1 $\alpha$, SURVIVIN, KLK-10 and cFLIP increased in ChaGo-K-1 cells upon hCG treatment (Fig. 3a-c). Several of these factors were transcriptionally and translationally upregulated in COLO-205 cells upon hCG treatment as well (Additional file 4: Figure S4). A
A

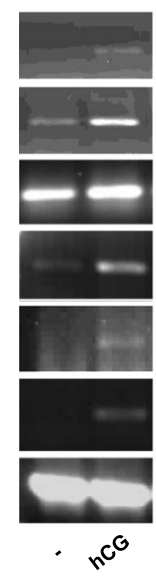

B

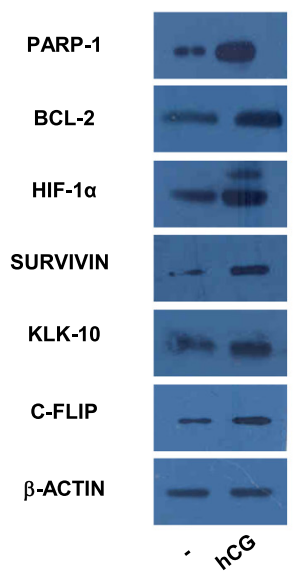

C
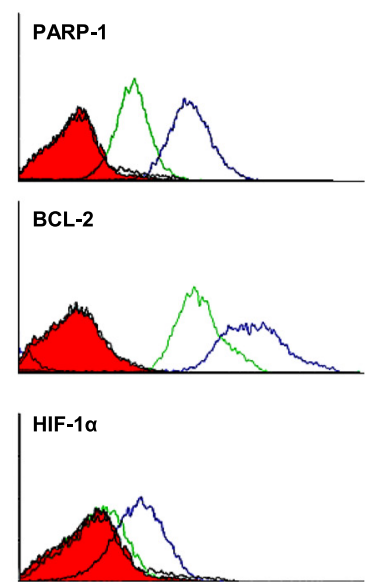

SURVIVIN

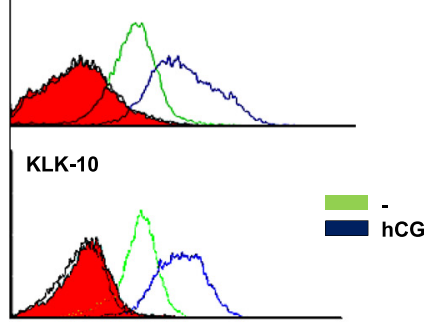

C-FLIP

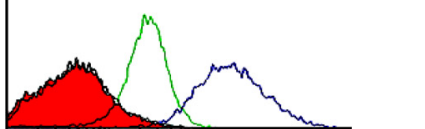

D

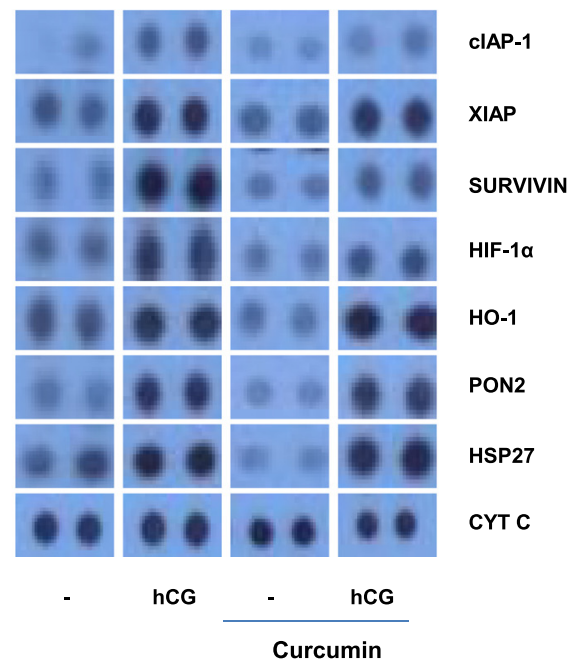

Fig. 3 hCG increases mRNA and expression levels of molecules associated with chemo-resistance, apoptosis and cell stress in tumor cells. a Semi-quantitative RT-PCR of molecules associated with chemo-resistance upon incubation of ChaGo-K-1 cells with medium or medium supplemented with hCG. $\beta$-ACTIN was employed as loading control. b Western blot of molecules associated with chemo-resistance upon incubation of ChaGo-K-1 cells with medium or medium supplemented with hCG. $\beta$-ACTIN was employed as loading control. c Flow cytometric analysis of molecules associated with chemo-resistance upon incubation of ChaGo-K-1 cells with medium or medium supplemented with hCG. Cells were permeabilized and stained with the respective antibodies. Filled red profiles indicate secondary antibody controls, green profiles indicate control cells and blue profile cells incubated with hCG. Data in A-C representative of four independent experiments. d Array dot blot analysis on ChaGo-K-1 cells incubated with medium, hCG, curcumin, or with hCG + curcumin. Expression levels of proteins associated with inhibition of apoptosis, chemo-resistance and protection from cell stress are shown. Cytochrome c (CYT C) was employed as loading control 
dot blot array capable of detecting thirty five apoptosisand stress regulatory response-related proteins was employed to confirm and extend these findings. ChaGo-K-1 cells incubated with hCG demonstrated increases in the levels of cIAP-1, XIAP and SURVIVIN (inhibitors of apoptotic proteins), HIF- $1 \alpha, \mathrm{HO}-1$ (associated with chemo-resistance and tumorigenesis), and PON2 and HSP27 (associated with protection from cell stress). Incubation with curcumin alone caused observable decreases in the levels of several of these molecules. Significantly, levels of these chemo-protective molecules remained high even in cells treated with apoptosis-inducing doses of curcumin in the presence of hCG (Fig. 3d).

HIF- $1 \alpha$, HO-1 and SURVIVIN were selected for further study, based on the weight of evidence linking them with chemo-resistance and tumorigenesis [23]; further, NRF-2 was also chosen, given its role up-stream of these molecules [24]. Specific siRNAs designed to target these molecules decreased transcript and protein levels in a dose-dependent manner (Fig. 4a). As anticipated, decreased expression of SURVIVIN and HO-1 levels were observed when siRNA against HIF- $1 \alpha$ and NRF-2 was respectively employed (Additional file 5: Figure S5).

To investigate the roles of HIF- $1 \alpha, \mathrm{HO}-1, \mathrm{NRF}-2$ and SURVIVIN in hCG-induced chemo-resistance, ChaGo-K-1 cells transfected with individual siRNAs were incubated with hCG and later exposed to either tamoxifen or curcumin. Silencing the proximal factor NRF-2 and the distal factor SURVIVIN either fully or substantially reversed the protection rendered by hCG against both drugs. Addition of siRNA to HO-1 or HIF- $1 \alpha$, on the other hand, had more modest or minimal effects, depending on the nature of the toxic insult (Fig. 4 b-e).

\section{Role of IL-6 derived from non-transformed cells in hCG-induced chemo-resistance}

Previous literature documents the production IL-6 (a cytokine associated with the development of chemoresistance $[16,25])$ by macrophages under the influence of tumor-derived factors [26]. The ability of recombinant IL-6 to induce protection against curcumin was verified on COLO-205 and ChaGo-K-1 (Fig. 5a). hCG was
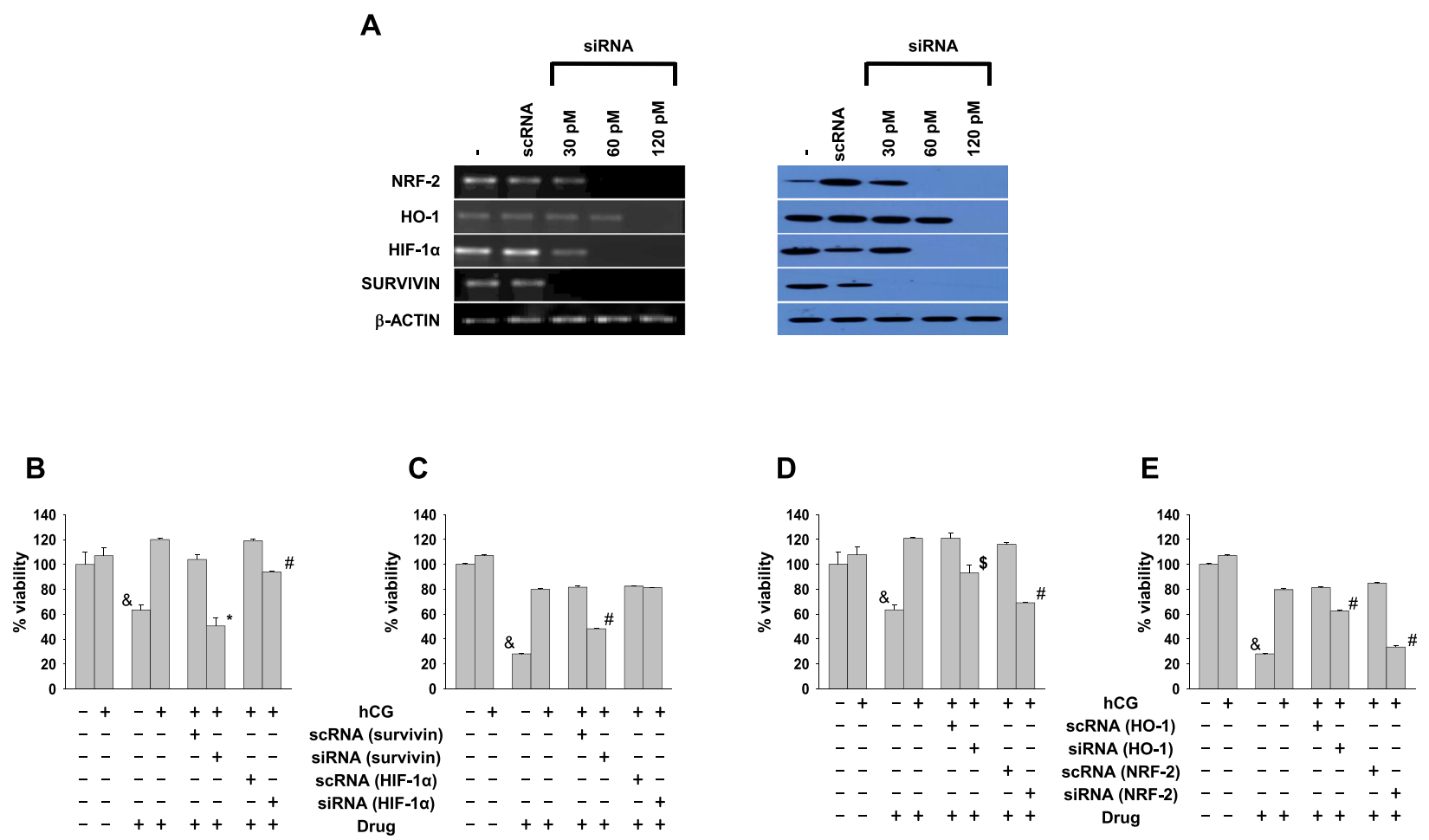

Fig. 4 Down-modulation of SURVIVIN, HIF-1a, HO-1 and NRF-2 decreases hCG-induced chemo-resistance. a mRNA levels by semi-quantitative RT-PCR (left panel) and protein levels by Western blot (right panel) of SURVIVIN, HIF 1-a, HO-1 and NRF-2 upon transfection of respective siRNAs in ChaGo-K-1 cells. scRNA: scrambled RNA control. $\beta$-ACTIN was employed as loading control. b-e Cell viability analysis of ChaGo-K-1 cells individually transfected with siRNAs against SURVIVIN, HIF 1-a, HO-1 and NRF-2 incubated with hCG and later exposed to (b, d) tamoxifen or (c, e) curcumin. scRNA: scrambled RNA control. For b-e, means \pm SEM of four independent experiments (with three replicates) are shown. In each case, data has been individually normalized to control cultures. ( ${ }^{\&} p<0.0003$ vs drug + hCG; ${ }^{*} p<0.003,{ }^{\#} p<0.0003$, ${ }^{\$} p<0.03$ vs hCG + respective scRNA + respective drug) 


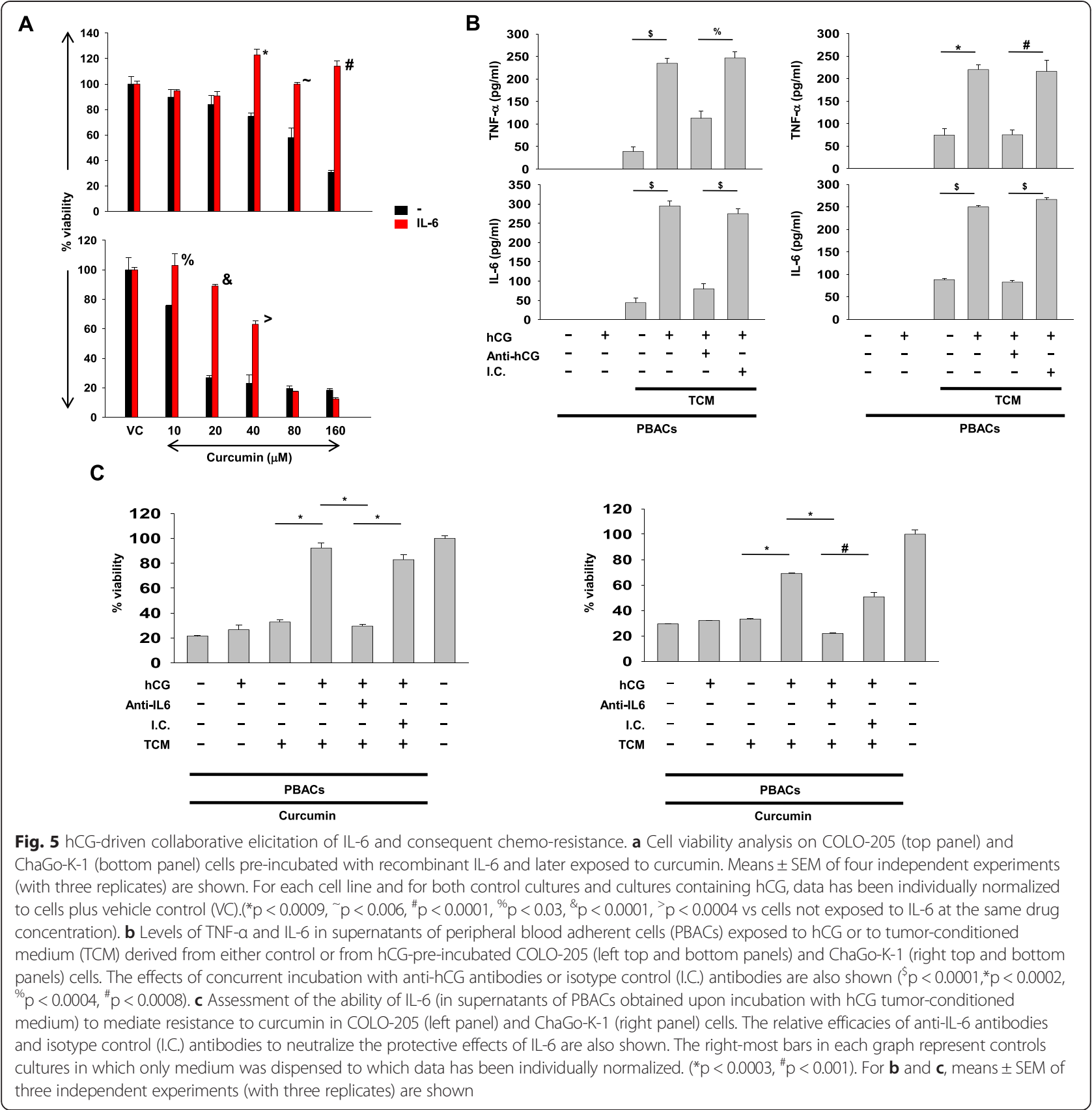

incapable of inducing the secretion of IL- 6 or TNF- $\alpha$ from tumor cells (data not shown) or from PBAC (Fig. 5b). However, heightened levels of IL-6 and TNF- $\alpha$ were observed in supernatants of human PBACs incubated with hCG-primed tumor conditioned medium (Fig. 5b). Such PBAC supernatants, when incubated with naive COLO-205 and ChaGo-K-1 cells, induced resistance to curcumin-mediated loss of viability; anti-IL-6 neutralizing antibodies negated this protective effect (Fig. 5c). These results suggest chemo-resistance can arise as a consequence of the interaction between tumor cells and normal cells, with hCG being the intermediary.
Effects of anti-hCG immunization and chemotherapy in tumor-bearing mice

Anti-hCG vaccination restricts the growth of murine tumors in vivo [27-29], data which validates the use of surrogate syngeneic immunization protocols.

All C57BL/6 mice injected with LLC1 cells generated tumors; administration of the vehicles had no effect on tumor incidence or volume. In animals receiving either immunotherapy (the hCG $\beta$-TT vaccine) or chemotherapy (curcumin), tumor incidence was reduced to $50 \%$; tumors that did arise demonstrated significantly smaller volumes, as assessed on Day 57 post-tumor implantation. The 
consequences of combination immunotherapy and chemotherapy on tumor growth were also subsequently assessed. Co-administration had effects on multiple parameters; while tumor incidence was further reduced, mean tumor volumes were significantly lower than those observed upon individual immunotherapy or chemotherapy. Further, there was an extended lag period before the appearance of tumors (Fig. 6 a, b). Kaplan-Meier analysis re-iterated the benefits of the combinatorial approach on animal survival. Mortality rates in animals treated with the vehicles were similar to those observed in untreated animals, with all animals in both groups succumbing by Day 70. Curcumin treatment and anti-hCG vaccination significantly improved survival over these control groups when individually administered; there was no difference in animal survival between chemotherapy and immunotherapy. Importantly, treatment with immunotherapy in combination with chemotherapy led to significant improvements in survival over both treatments administered individually (Fig. 6c).

\section{Synergy between anti-hCG antibodies and curcumin}

The simultaneous addition of anti-hCG antibodies and curcumin on ChaGo-K-1 cells induced significant

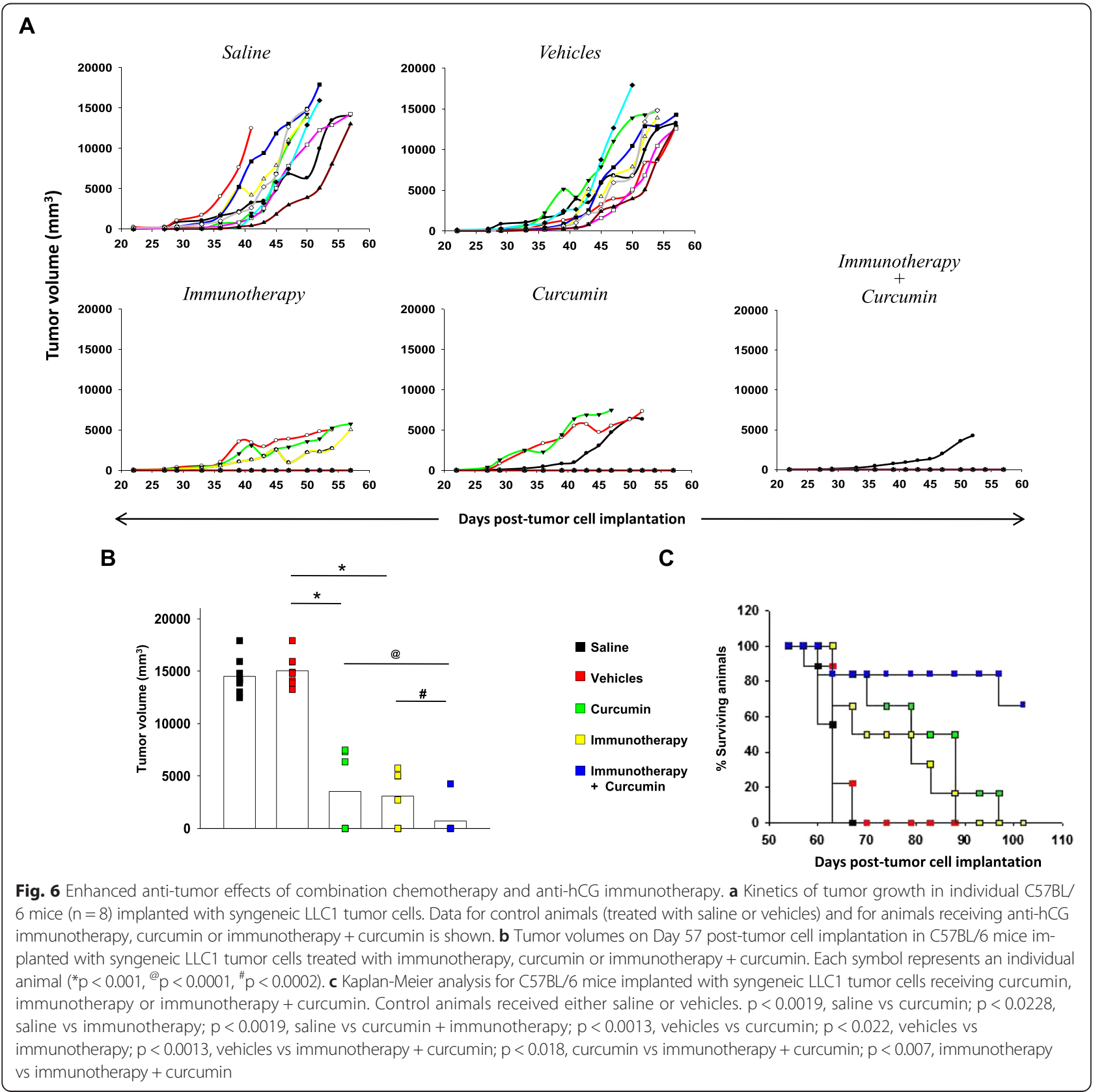


inhibitory effects over the addition of individual moieties (Additional file 6: Figure S6A).

A graphical representation of the analysis for the determination of the Combination Index (C.I.) is depicted in Additional file 6: Figure S6B. $\mathrm{IC}_{50}$ values for curcumin and anti-hCG antibodies are plotted as $\left(\mathrm{IC}_{50}\right.$ antibody, $0)$, (0, $\mathrm{IC}_{50}$ curcumin) and $\mathrm{C}_{50}$ antibody, $\mathrm{C}_{50}$ curcumin (for two representative data points) as dot plots. For the two data points, C.I. values were 0.699 (red) and 0.711 (green), values which constitute evidence of synergy, being less than one.

\section{Discussion}

Growing evidence suggests that tumors secrete factors that can affect either tumor cells themselves or cells in the microenvironment to regulate growth and progression [17].

The demonstration of hCG in several non-trophoblastic tumors such as pancreatic and biliary cancer [4], urothelial cancer [5] and lung cancer [6] has spurred interest in patho-physiological roles the hormone might play, particularly since elevated levels of the hormone are often correlated with higher metastatic potential [11], unresponsiveness to drugs and poor patient prognosis $[8,9,20]$. Though the increase in the viability and proliferation of tumor cells upon exposure to exogenous hCG in this study are in line with similar findings by previous investigators, the molecular mechanisms linking the hormone to chemo-resistance (a major determinant of poor prognosis) have not been investigated in any detail, save for a study demonstrating the ability of hCG to induce resistance to cisplatin in ovarian cancer cells [30].

The current study provides substantial evidence of the chemo-protective effects of hCG. While tamoxifen has been widely employed in the treatment of human cancer, several studies have demonstrated the toxic effects curcumin on tumor cells of various lineages; it is an antioxidant and anti-inflammatory agent, and an inhibitor of NF-kappa B. Interestingly, curcumin has also been demonstrated to enhance sensitivity of tumor cells to a variety of drugs and hence has been considered a "chemosensitizing" agent [31]. hCG also reduced etoposide- and 5-FU- mediated loss of tumor cell viability (Additional file 7: Figure S7A). Two additional read-outs supported the idea that hCG has trophic effects on tumor cells. Firstly, hCG ameliorated the suppression of proliferation (as assessed by the uptake of $\left[{ }^{3} \mathrm{H}\right]$-Thymidine) induced by curcumin, tamoxifen and 5-FU (Additional file 7: Figure S7B). Secondly, while 5-FU caused a decrease in basal levels of secretion of IL-8 (a cytokine associated with tumorigenesis) from COLO205 cells, pre-incubation with hCG prevented such decreases (Additional file 7: Figure S7C). Since the drugs employed in this study act via different mechanisms to induce cytotoxicity, the study demonstrated that the protective effects of hCG were wide-ranging, generic and not restricted to a specific pathway.

While several genes have been implicated in chemoresistance, it was not the primary aim of this manuscript to assess the effects of hCG on them all. Rather, this study had a more focussed objective. The genes selected for study in this work were primarily chosen on the basis of two criteria: Firstly, all had previously been shown to be modulated by hCG (in reproductive tissues but not in cancer cells) and secondly, all had also been shown to play a role in chemoresistance (mediated by moieties other than hCG, either in reproductive tissues or in cancer cells). Application of these dual criteria resulted in the selection of genes that were of a more generic nature, not associated with a particular drug.

Incubation of tumor cells with hCG resulted in an increased expression of c-FLIP, an endogenous inhibitor of caspase 8 . Since caspase 8 acts to up-regulate levels of caspase 3, these results are in line with the observed decrease in the conversion of pro-caspase 3 to caspase 3 upon incubation of tumor cells with hCG. Increase in BCL-2 upon hCG treatment in human colorectal and lung cancer cells in the current study suggests that inhibition of the mitochondrial pathway of apoptosis also possibly contributes to hCG-induced protection from drug-induced tumor cell death, although this postulate awaits formal verification.

hCG-induced effects on tumor cells appear to be the result of multiple collaborative pathways. Down-stream events can be postulated to occur post the proliferative responses induced by hCG, since uncontrolled proliferation can increase oxidative stress, endoplasmic reticulum (ER) stress and genomic instability-induced stress [32], a likely result of which is apoptosis. Tumor cells respond to such threats by up-modulation of ER stress regulators like BCL-2, HIF-1 $\alpha$, PARP-1, HSP27, HO-1 and PON2, all molecules shown to be up-modulated in tumor cells upon the addition of hCG in this study; hCG also enhanced levels of IAPs such as SURVIVIN, cIAP-1 and XIAP, known contributors to chemo-resistance. These results imply that hCG may act as an anti-stress regulator. The reversal of hCG-induced chemo-resistance in cells depleted of NRF-2 (a transcription factor upstream of HIF- $1 \alpha$ and HO-1) and SURVIVIN in the current study suggests that hCG can exert its influence on both the proximal and distal ends of the apoptotic pathway. The fact that hCG provides protection against drugs which act via distinct mechanisms, as well against nutrient exhaustion-induced death (data not shown), supports this conclusion.

Increasing evidence links TLR signalling with tumorigenesis and the development of chemo-resistance [13, 22 , 33]. In the current study, hCG increased the 
transcription and expression of TLR1, TLR3, TLR8 and TLR9; interestingly, and the combined addition of hCG with ligands for these TLRs (along with many others) resulted in enhanced chemo-protective effects, beyond those observed when hCG and the TLR ligands were individually employed. Because of the nature of some of the ligands employed in this study as well as the fact that some TLRs exist as signalling heterodimers, the results may not be always attributable to individual TLRs. For example, while HKLM appears to be an exclusive TLR2 agonist, Pam3CSK4 binds the TLR1/TLR2 dimer and FSL-1 the TLR2/TLR6 dimer; outcomes using Pam3CSK4 and FSL-1 may therefore be a consequence of TLR2 triggering. Regardless of these fine distinctions and in light of the data with other ligands, it does appear that NF- $\mathrm{KB}$ may comprise a central event, where both MyD88dependent (all TLRs with the exception of TLR3) and TRIF-dependent (TLR3 and TLR4) pathways converge [34]. The global enumeration of genes that are modulated in response to dual ligand stimulation is underway.

Data obtained upon analysis of signalling events in cells exposed to hCG, TLR ligand and chemotherapeutic drug is strongly suggestive of tri-molecular synergy in some instances. Of particular interest in this regard were signalling synergies between hCG and the TLR9 ligand ODN2006 for JNK phosphorylation and between hCG and the TLR8 ligand ssRNA40 for ERK phosphorylation, given the fact that both TLR8 and TLR9 were upmodulated by hCG. Based on currently available and emerging data, the following scenario can be envisaged: Assault by chemotherapeutic drugs induces the release endogenous TLR ligands from cells as they die. In the cells that survive, hCG-mediated up-modulation of TLR expression contributes to enhanced hCG-TLR intracellular signalling; the consequence of these events is the creation of an environment characterized by heightened levels of stress regulatory mediators which drive chemoresistance (Additional file 8: Figure S8). The sustained activation of MAP kinase signalling pathways, which may contribute to these events, may have further implications as well; tumorigenesis is often characterized by enhanced and sustained signalling via these pathways $[35,36]$. Indeed, inhibition of the JNK and ERK signaling pathways are considered valid therapeutic strategies. Ligands capable of triggering such events in tumor cells (particularly those not arising as a result of mutational events) are of obvious interest.

Of the many accessory cells known to augment tumor progression, macrophages are of particular interest [37]. Previous studies have suggested a role for IL- 6 in the development of chemo-resistance [16, 25]. Tumor-derived versican (a proteoglycan which sequesters chemokines and acts as a chemo-attractant for inflammatory cells in the tumor milieu) can stimulate resident macrophages to secrete IL- 6 and TNF- $\alpha$ in a TLR- 2 dependent manner [26]. Previous work in the lab has demonstrated the ability of hCG to enhance the secretion of versican from tumor cells, resulting in the release of these inflammatory cytokines in a TLR-2 dependent manner (data not shown). The current work demonstrates that the enhanced levels of macrophage-elicited IL-6 can mediate chemo-resistance. These results suggest that, in addition to mediating direct chemo-protective effects, hCG can also initiate cross-talk between tumor cells and macrophages to induce the generation of chemo-protective cytokines.

On-going studies have established that implantation of tumor cells in mice transgenic for $\beta$ hCG results in increased tumor incidence and higher tumor volume. In addition, transcription of several of the genes identified in this study is up-modulated in tumors implanted in these animals (data not shown).

In view of the known and suspected roles of hCG in tumorigenesis, anti-hCG vaccination is increasingly considered an attractive option. A vaccine based on the Cterminal region of hCG induced beneficial effects in patients of colorectal cancer [38]. Previous studies have also described the ameliorating effects on the reproductive axis of anti-hCG immunization in hCG $\beta$ transgenic mice which express ovarian hyperplasia and pituitary tumors [39]. Most other work in the area involves the use of surrogate murine systems [27-29]. One of these studies [28] provided evidence for adjuvantic and anti-tumor effects of MIP in anti-hCG vaccination, work that was based on previous published reports on the anti-tumor potency of MIP in mice [40] and in humans [41]. While IFA has often been employed as an adjuvant in humans with encouraging results [42], the other components in the formulations employed in this study have been approved for use in humans, with an analogous vaccine having previously demonstrated the ability to break tolerance towards hCG and exert anti-fertility effects in women [43].

Concurrent chemotherapy is believed to potentiate immunotherapeutic responses, possibly by increasing inflammation in the target area [44]. Conversely, immunotherapy, particularly directed against a soluble, potential tumor-promoting moiety like hCG that induces chemo-resistance, can potentially enhance the therapeutic efficacy of chemotherapy as well. The current study, using a validated murine model, suggests that the combination of chemo-therapy and immunotherapy offers distinct advantages; add-on anti-hCG immunotherapy improved three critical parameters of tumorigenesis in animals treated with curcumin: tumor incidence, tumor volume and animal survival. Quite conceivably, such combination regimens would permit reduction in chemotherapeutic drug dose, thereby serving to also ameliorate associated toxicities. 


\section{Conclusions}

Tumor-derived gonadotropin has been associated with reduced survival. The novelty of the current study lies in the elucidation of some of the mechanistic details of the hormone's tumor-protective effects in the face of drug assault. The data uniquely demonstrates that hCG elicits pro-survival signals which interfere with the apoptotic cascade and can enhance the ability to counter cellular stress. That the additional presence of TLR ligands was shown to greatly enhance chemoresistance supports the testable, hitherto unconsidered postulate that dying tumor cells (a potential source of endogenous TLR ligands) may engender increased resistance in tumor cells that survive. The collaborative elicitation of IL-6 from monocytes presents an alternative mechanism of hCGmediated chemo-resistance. The data also suggest that combination immunotherapy-chemotherapy protocols, using moieties and materials already in human use, may result in substantial beneficial effects in patients carrying gonadotropin-sensitive tumors.

\section{Additional files}

Additional file 1: Figure S1. Sequences of primers employed in RT-PCR analysis. (PDF $159 \mathrm{~kb}$ )

Additional file 2: Figure S2. Increased transcription and expression of TLRs in COLO-205 tumor cells incubated with hCG. Semi-quantitative RT-PCR (left panels) and Western blot (right panels) analysis of TLRs upon incubation of COLO-205 cells with medium or hCG. $\beta$-ACTIN was employed as loading control. (PDF $24 \mathrm{~kb}$ )

Additional file 3: Figure S3. $\mathrm{hCG}$ and TLR ligands enhance chemoresistance. Cell viability analysis on COLO-205 cells incubated with hCG, individual TLR ligands and tamoxifen in combination. H: hCG; P: Pam3CSK4; HK: HKLM; PI: Poly I:C; L: LPS; FL: Flagellin; F: FSL-1; I: Imiquimod; ss: ssRNA40; O: ODN2006. Means \pm SEM of three independent experiments (with three replicates) are shown. In each case, data has been individually normalized to control cultures. $\left({ }^{@} p<0.0006\right.$ vs medium; ${ }^{\#} p<0.0001, \$ p<$ 0.002 vs hCG + tamoxifen; ${ }^{\&} p<0.0001 ;{ }^{\circ} p<0.004,{ }^{\wedge} p<0.02$ vs hCG + TLR ligand). (PDF $24 \mathrm{~kb}$ )

Additional file 4: Figure S4. $\mathrm{hCG}$ increases mRNA and expression levels of molecules associated with chemo-resistance, apoptosis and cell stress in tumor cells. A. Semi-quantitative RT-PCR of molecules associated with chemo-resistance upon incubation of COLO-205 cells with medium or medium supplemented with hCG. $\beta$-ACTIN was employed as loading control. B. Western blot of molecules associated with chemo-resistance upon incubation of COLO-205 cells with medium or medium supplemented with hCG. $\beta$-ACTIN was employed as loading control. C. Flow cytometric analysis of molecules associated with chemo-resistance upon incubation of COLO-205 cells with medium or medium supplemented with hCG. Cells were permeabilized and stained with the respective antibodies. Filled red profiles indicate secondary antibody controls, green profiles indicate control cells and blue profile cells incubated with hCG. Data representative of four independent experiments. (PDF $24 \mathrm{~kb}$ )

Additional file 5: Figure S5. "Off target" effects of siRNAs (at 120 pmol) against SURVIVIN, HIF-1a, HO-1 and NRF-2, when individually employed, against the other three targets. $\beta$-ACTIN was employed as loading control. scRNA: scrambled RNA. (PDF $24 \mathrm{~kb}$ )

Additional file 6: Figure S6. The effects of anti-hCG antibodies and curcumin, added individually and in combination, on the viability of ChaGo-K-1 cells. A. Representative MTT analysis at an antibody dose of $2 \mu \mathrm{g} / \mathrm{ml}$ and the indicated doses of curcumin. Means \pm SEM of three independent experiments (with three replicates) are shown. In each case, data has been individually normalized to control cultures. ${ }^{*} p<0.006$; ${ }^{* *} p<0.0008 ;{ }^{* * *} p<0.0007 ; \quad p<0.04 ; \# p<0.0003 ; \#$; $p<0.0001$. Isotype control antibodies: Negative control for anti-hCG antibodies. B. Assessment of synergistic effects of curcumin and anti-hCG antibodies on the viability of ChaGo-K-1 cells. The Combination Index (C.I.) was calculated (as described in Materials and Methods) for several data points, two of which are depicted. Red data point: 0.699; Green data point: 0.711. (PDF 24 kb)

Additional file 7: Figure S7. Effects of hCG on drug-induced loss of cell viability, proliferation and cytokine secretion. A. Effects on 5-Fluorouracil(top panel) or Etoposide- (bottom panel) -induced decrease in the viability of COLO-205 cells. Means \pm SEM of four independent experiments (with three replicates) are shown. In each case, and for both control cultures and cultures containing hCG, data has been individually normalized to cells plus vehicle control (VC). ${ }^{\$} p<0.0009$, ${ }^{*} p<0.005,{ }^{*} p<0.0001,{ }^{\%} p<0.0006$ vs cells not exposed to h(G). B. Effects on drug-induced decreases in the incorporation of $\left[{ }^{3} \mathrm{H}\right]$-Thymidine in LLC1 cells. $\left({ }^{*} \mathrm{p}<0.0001\right.$ vs cells not exposed to hCG) VC: Vehicle control. C. Effects on 5-FU -induced decreases in the secretion of IL-8 from COLO-205 cells. "Medium" refers to RPMI 1640 with $10 \%$ fetal bovine serum. TCM: Tumor-conditioned medium. For A-C, means \pm SEM of four independent experiments (with three replicates) are shown ( $<p<0.0002$ vs control cells; $" p<0.0003$ vs 5 -FU treated cells). (PDF $24 \mathrm{~kb})$

Additional file 8: Figure S8. Postulated tri-molecular synergy between chemotherapeutic drugs, TLR ligands and hCG in the development of chemo-resistance in tumor cells. Upward arrows indicate up-modulation. See text for details. (PDF $201 \mathrm{~kb}$ )

\section{Abbreviations}

ERK: Extracellular signal-regulated kinase; hCG: Human Chorionic Gonadotropin; HO-1: Hemeoxygenase 1; IL-6: Interleukin 6; TLR: Toll-like receptor; TNF: Tumor necrosis factor.

\section{Competing interests}

The authors declare that they have no competing interests.

\section{Authors' contributions}

SS conducted experiments, helped draft the manuscript and analyzed data. PS and BK conducted experiments. OS conceived the study. RP conceived the study, designed the experiments, analyzed data and finalized the manuscript. All authors read and approved the final manuscript.

\section{Acknowledgments}

The authors would like to thank Mr. Ashok Kumar, Mr. Ramesh Chand and Mr. Suraj Kumar for technical assistance. This work was supported by an extra-mural grant from the Department of Biotechnology, Government of India (BT/PR/5861/Med/14/705/2005) to OS and RP. Core funds from the National Institute of Immunology were also utilized.

Received: 3 September 2015 Accepted: 19 November 2015 Published online: 25 November 2015

\section{References}

1. Braunstein GD. Evidence favoring human chorionic gonadotropin as the physiological 'rescuer' of the corpus luteum during early pregnancy. Early Pregnancy. 1996;2:183-90.

2. Berndt S, Perrier S, Blacher S, Pequeux C, Lorquet S, Munaut C, et al. Angiogenic activity of human chorionic gonadotropin through LH receptor activation on endothelial and epithelial cells of the endometrium. FASEB J. 2006:20:2630-2.

3. Fluhr H, Bischof-Islami D, Krenzer S, Licht P, Bischof P, Zygmunt M. Human chorionic gonadotropin stimulates matrix metalloproteinases-2 and -9 in cytotrophoblastic cells and decreases tissue inhibitor of metalloproteinases-1, -2 , and -3 in decidualized endometrial stromal cells. Fertil Steril. 2008; 90:1390-5.

4. Alfthan $\mathrm{H}$, Haglund C, Roberts P, Stenman UH. Elevation of free beta subunit of human choriogonadotropin and core beta fragment of human choriogonadotropin in the serum and urine of patients with malignant pancreatic and biliary disease. Cancer Res. 1992;52:4628-33. 
5. Iles RK, Jenkins BJ, Oliver RTD, Blandy JP, Chard T. Beta human chorionic gonadotrophin in serum and urine. A marker for metastatic urothelial cancer. Br J Urol. 1989;64:241-4.

6. Yoshimura M, Nishimura R, Murotani A, Miyamoto Y, Nakagawa T, Hasegawa $K$, et al. Assessment of urinary beta-core fragment of human chorionic gonadotropin as a new tumor marker of lung cancer. Cancer. 1994;73:2745-52.

7. Gillott DJ, lles RK, Chard T. The effects of beta-human chorionic gonadotrophin on the in vitro growth of bladder cancer cell lines. $\mathrm{Br}$ J Cancer. 1996;73:323-6.

8. Sheaff MT, Martin JE, Badenoch DF, Baithun SI. beta hCG as a prognostic marker in adenocarcinoma of the prostate. J Clin Pathol. 1996:49:329-32.

9. Szturmowicz M, Wiatr E, Sakowicz A, Slodkowska J, Roszkowski K, Filipecki S, et al. The role of human chorionic gonadotropin beta subunit elevation in small-cell lung cancer patients. J Cancer Res Clin Oncol. 1995;121:309-12.

10. Moutzouris G, Yannopoulos D, Barbatis C, Zaharof A, Theodorou C. Is beta-human chorionic gonadotrophin production by transitional cell carcinoma of the bladder a marker of aggressive disease and resistance to radiotherapy? Br J Urol. 1993;72:907-9.

11. Acevedo HF, Hartsock RJ. Metastatic phenotype correlates with high expression of membrane-associated complete beta-human chorionic gonadotropin in vivo. Cancer. 1996;78:2388-99.

12. Huhtaniemi I, Rulli S, Ahtiainen P, Poutanen M. Multiple sites of tumorigenesis in transgenic mice overproducing hCG. Mol Cell Endocrinol. 2005;234:117-26.

13. Cherfils-Vicini J, Platonova S, Gillard M, Laurans L, Validire P, Caliandro R, et al. Triggering of TLR7 and TLR8 expressed by human lung cancer cells induces cell survival and chemoresistance. J Clin Invest. 2010;120:1285-97.

14. Hernandez-Luna MA, Rocha-Zavaleta L, Vega MI, Huerta-Yepez S. Hypoxia inducible factor-1alpha induces chemoresistance phenotype in nonHodgkin lymphoma cell line via up-regulation of Bcl-xL. Leuk Lymphoma. 2013;54:1048-55.

15. Wang X, Xu J, Ju S, Ni H, Zhu J, Wang H. Livin gene plays a role in drug resistance of colon cancer cells. Clin Biochem. 2010;43:655-60.

16. Wang $Y$, Niu XL, Qu Y, Wu J, Zhu YQ, Sun WJ, et al. Autocrine production of interleukin- 6 confers cisplatin and paclitaxel resistance in ovarian cancer cells. Cancer Lett. 2010;295:110-23.

17. Albini A, Sporn MB. The tumour microenvironment as a target for chemoprevention. Nat Rev Cancer. 2007;7:139-47.

18. Mandokhot A, Pal R, Nagpal S, Chauhan VS, Ahlawat S, Singh O. Humoral hyporesponsiveness to a conjugate contraceptive vaccine and its bypass by diverse carriers using permissible adjuvant. Clin Exp Immunol. 2000;122:101-8.

19. Zhao L, Au JL, Wientjes MG. Comparison of methods for evaluating drugdrug interaction. Front Biosci (Elite Ed). 2010;2:241-9.

20. Szturmowicz M, Slodkowska J, Zych J, Rudzinski P, Sakowicz A, RowinskaZakrzewska E. Frequency and clinical significance of beta-subunit human chorionic gonadotropin expression in non-small cell lung cancer patients. Tumour Biol. 1999;20:99-104.

21. Plati J, Bucur O, Khosravi-Far R. Dysregulation of apoptotic signaling in cancer: molecular mechanisms and therapeutic opportunities. J Cell Biochem. 2008;104:1124-49.

22. Ioannou S, Voulgarelis M. Toll-like receptors, tissue injury, and tumourigenesis. Mediators Inflamm. 2010; doi:10.1155/2010/581837

23. Hockel M, Vaupel P. Tumor hypoxia: definitions and current clinical, biologic, and molecular aspects. J Natl Cancer Inst. 2001;93:266-76.

24. Ji X, Wang H, Zhu J, Zhu L, Pan H, Li W, et al. Knockdown of Nrf2 suppresses glioblastoma angiogenesis by inhibiting hypoxia-induced activation of HIF-1alpha. Int J Cancer. 2014;135:574-84.

25. Conze D, Weiss L, Regen PS, Bhushan A, Weaver D, Johnson P, et al. Autocrine production of interleukin 6 causes multidrug resistance in breast cancer cells. Cancer Res. 2001;61:8851-8.

26. Kim S, Takahashi H, Lin WW, Descargues P, Grivennikov S, Kim Y, et al. Carcinoma-produced factors activate myeloid cells through TLR2 to stimulate metastasis. Nature. 2009;457:102-6.

27. Acevedo HF, Raikow RB, Powell JE, Stevens VC. Effects of immunization against human choriogonadotropin on the growth of transplanted Lewis lung carcinoma and spontaneous mammary adenocarcinoma in mice. Cancer Detect Prev Suppl. 1987;1:477-86.

28. Bose A, Huhtaniemi I, Singh O, Pal R. Synergistic activation of innate and adaptive immune mechanisms in the treatment of gonadotropin-sensitive tumors. PLoS One. 2013; doi:10.1371/journal.pone.0061288
29. Yankai Z, Rong Y, Yi H, Wentao L, Rongyue C, Ming Y, et al. Ten tandem repeats of beta-hCG 109-118 enhance immunogenicity and anti-tumor effects of beta-hCG C-terminal peptide carried by mycobacterial heat-shock protein HSP65. Biochem Biophys Res Commun. 2006;345:1365-71.

30. Kuroda H, Mandai M, Konishi I, Yura Y, Tsuruta Y, Hamid AA, et al. Human chorionic gonadotropin ( $\mathrm{hCG}$ ) inhibits cisplatin-induced apoptosis in ovarian cancer cells: possible role of up-regulation of insulin-like growth factor-1 by hCG. Int J Cancer. 1998;76:571-8.

31. Vinod BS, Antony J, Nair HH, Puliyappadamba VT, Saikia M, Narayanan SS, et al. Mechanistic evaluation of the signaling events regulating curcuminmediated chemosensitization of breast cancer cells to 5-fluorouracil. Cell Death Dis. 2013;4:e505. doi:10.1038/cddis.2013.26.

32. Mahadevan NR, Zanetti M. Tumor stress inside out: cell-extrinsic effects of the unfolded protein response in tumor cells modulate the immunological landscape of the tumor microenvironment. J Immunol. 2011;187:4403-9.

33. Sun Z, Luo Q, Ye D, Chen W, Chen F. Role of toll-like receptor 4 on the immune escape of human oral squamous cell carcinoma and resistance of cisplatin-induced apoptosis. Mol Cancer. 2012;11:33. doi:10.1186/1476-4598-11-33.

34. Kawai T, Akira S. The role of pattern-recognition receptors in innate immunity: update on Toll-like receptors. Nat Immunol. 2010;11:373-84.

35. Samatar AA, Poulikakos PI. Targeting RAS-ERK signalling in cancer: promises and challenges. Nat Rev Drug Discov. 2014;13:928-42.

36. Bubici C, Papa S. JNK signalling in cancer: in need of new, smarter therapeutic targets. Br J Pharmacol. 2014;171:24-37.

37. Whitworth PW, Pak CC, Esgro J, Kleinerman ES, Fidler IJ. Macrophages and cancer. Cancer Metastasis Rev. 1990;8:319-51.

38. Moulton HM, Yoshihara PH, Mason DH, Iversen PL, Triozzi PL. Active specific immunotherapy with a beta-human chorionic gonadotropin peptide vaccine in patients with metastatic colorectal cancer: antibody response is associated with improved survival. Clin Cancer Res. 2002;8:2044-51.

39. Sachdeva R, Bhardwaj N, Huhtaniemi I, Aggrawal U, Jain SK, Zaidi R, et al. Transgenesis-mediated reproductive dysfunction and tumorigenesis: effects of immunological neutralization. PLoS One. 2012;7(11):e51125. doi:10.1371/ journal.pone.0051125.

40. Ahmad F, Mani J, Kumar P, Haridas S, Upadhyay P, Bhaskar S. Activation of anti-tumor immune response and reduction of regulatory $T$ cells with Mycobacterium indicus pranii (MIP) therapy in tumor bearing mice. PLoS One. 2011;6(9):e25424. doi:10.1371/journal.pone.0025424.

41. Sur PK, Dastidar AG. Role of mycobacterium $w$ as adjuvant treatment of lung cancer (non-small cell lung cancer). J Indian Med Assoc. 2003;101:118-20.

42. Salerno EP, Shea SM, Olson WC, Petroni GR, Smolkin ME, McSkimming C, et al. Activation, dysfunction and retention of T cells in vaccine sites after injection of incomplete Freund's adjuvant, with or without peptide. Cancer Immunol Immunother. 2013;62:1149-59.

43. Talwar GP, Singh O, Pal R, Chatterjee N, Sahai P, Dhall K, et al. A vaccine that prevents pregnancy in women. Proc Natl Acad Sci U S A. 1994;91:8532-6.

44. Gabrilovich DI. Combination of chemotherapy and immunotherapy for cancer: a paradigm revisited. Lancet Oncol. 2007;8:2-3.

\section{Submit your next manuscript to BioMed Central and we will help you at every step:}

- We accept pre-submission inquiries

- Our selector tool helps you to find the most relevant journal

- We provide round the clock customer support

- Convenient online submission

- Thorough peer review

- Inclusion in PubMed and all major indexing services

- Maximum visibility for your research

Submit your manuscript at www.biomedcentral.com/submit
C) BioMed Central 